\title{
Acalabrutinib (ACP-196): A Covalent Bruton Tyrosine Kinase Inhibitor with a Differentiated Selectivity and In Vivo Potency Profile『
}

\author{
Tjeerd Barf, Todd Covey, Raquel Izumi, Bas van de Kar, Michael Gulrajani, Bart van Lith, \\ Maaike van Hoek, Edwin de Zwart, Diana Mittag, Dennis Demont, Saskia Verkaik, \\ Fanny Krantz, Paul G. Pearson, Roger Ulrich, and Allard Kaptein
}

Acerta Pharma BV, Oss, The Netherlands

Received June 13, 2017; accepted August 31, 2017

\begin{abstract}
Several small-molecule Bruton tyrosine kinase (BTK) inhibitors are in development for B cell malignancies and autoimmune disorders, each characterized by distinct potency and selectivity patterns. Herein we describe the pharmacologic characterization of BTK inhibitor acalabrutinib [compound 1, ACP-196 (4-[8amino-3-[(2S)-1-but-2-ynoylpyrrolidin-2-yl]imidazo[1,5-a]pyrazin1 -yl]- $N$-(2-pyridyl)benzamide)]. Acalabrutinib possesses a reactive butynamide group that binds covalently to Cys481 in BTK. Relative to the other BTK inhibitors described here, the reduced intrinsic reactivity of acalabrutinib helps to limit inhibition of offtarget kinases having cysteine-mediated covalent binding potential. Acalabrutinib demonstrated higher biochemical and cellular selectivity than ibrutinib and spebrutinib (compounds 2 and 3 , respectively). Importantly, off-target kinases, such as epidermal growth factor receptor (EGFR) and interleukin 2-inducible T cell kinase (ITK), were not inhibited. Determination of the inhibitory
\end{abstract}

potential of anti-immunoglobulin M-induced CD69 expression in human peripheral blood mononuclear cells and whole blood demonstrated that acalabrutinib is a potent functional BTK inhibitor. In vivo evaluation in mice revealed that acalabrutinib is more potent than ibrutinib and spebrutinib. Preclinical and clinical studies showed that the level and duration of BTK occupancy correlates with in vivo efficacy. Evaluation of the pharmacokinetic properties of acalabrutinib in healthy adult volunteers demonstrated rapid absorption and fast elimination. In these healthy individuals, a single oral dose of $100 \mathrm{mg}$ showed approximately $99 \%$ median target coverage at 3 and 12 hours and around $90 \%$ at 24 hours in peripheral B cells. In conclusion, acalabrutinib is a BTK inhibitor with key pharmacologic differentiators versus ibrutinib and spebrutinib and is currently being evaluated in clinical trials.

\section{Introduction}

Bruton tyrosine kinase (BTK) is a TEC-family nonreceptor protein kinase expressed in B cells, myeloid cells, mast cells, and platelets. B cell receptor (BCR)-mediated signaling is essential for activation, proliferation, and survival of $\mathrm{B}$ lymphocytes, and BTK is an essential component of the BCR signaling cascade (Hendriks et al., 2014). Expression of BTK in B cell leukemias and lymphomas has also been reported (de Weers et al., 1993; Katz et al., 1994). Furthermore, BTK is involved in the regulation of Fc $\gamma \mathrm{R}$ signaling in myeloid cells (Jongstra-Bilen et al., 2008) and in mast cell degranulation after FceR1 activation (Ellmeier

https://doi.org/10.1124/jpet.117.242909.

S This article has supplemental material available at jpet.aspetjournals.org. et al., 2011). These features of BTK render it a very attractive target in treating B cell malignancies (Hendriks et al., 2014) and autoimmune disease (Whang and Chang, 2014). Several small-molecule inhibitors of BTK have progressed to the clinic (Table 1) and collectively demonstrate clinical validation of BTK inhibition in B cell malignancies. Most of the BTK inhibitors listed in Table 1 have been reported to bind in a covalent fashion to a cysteine residue (Cys481) at the rim of the ATP binding pocket of BTK (Pan et al., 2007; Norman, 2016). To date, ibrutinib is the only BTK inhibitor that has received marketing authorization for the treatment of $\mathrm{B}$ cell malignancies (Ponader and Burger, 2014); however, it is associated with adverse events not likely due to inhibition of BTK function, based on clinical observations in patients with X-linked agammaglobulinemia who have dysfunctional BTK (Winkelstein et al., 2006). These

ABBREVIATIONS: ADCC, antibody-dependent cellular cytoxicity; AUC, area under the concentration-time curve; BCR, B-cell receptor; BLK, B-lymphocyte kinase; BMX, bone marrow tyrosine kinase gene in chromosome X; BTK, Bruton's tyrosine kinase; CLL, chronic lymphocytic leukemia; ErbB, erythroblastosis oncogene B; EGFR (ErbB1), epidermal growth factor receptor; FACS, fluorescence-activated cell sorter; FBS, fetal bovine serum; FGR, Gardner-Rasheed feline sarcoma viral (v-fgr) oncogene homolog; FYN, Fgr/Yes related novel protein; HCK, hemopoietic cell kinase; hWB, human whole blood; IL, interleukin; IMAP, immobilized metal affinity for phosphochemicals; ITK, IL2-inducible T-cell kinase; JAK, janus-associated kinase; LCK, lymphocyte-specific protein tyrosine kinase; LYN, Lck/Yes novel; PBMC, peripheral blood mononuclear cell; PBS, phosphate-buffered saline; PD, pharmacodynamics; PK, pharmacokinetics; SRC, Rous sarcoma oncogene cellular homologue; SRR, structurereactivity relationship; TEC, tyrosine kinase expressed in hepatocellular carcinoma; Txk, T and X cell expressed kinase; XLA, X-linked agammaglobulinemia; YES, Yamaguchi sarcoma viral oncogene homologue. 
TABLE 1

Monotherapy clinical stage covalent BTK kinase inhibitors

\begin{tabular}{llcll}
\hline \multicolumn{1}{c}{ Compound } & \multicolumn{1}{c}{ Company } & Stage of Development $^{a}$ & Primary Therapeutic Area & \multicolumn{1}{c}{ Reference } \\
\hline Ibrutinib (Imbruvica) & J\&J, AbbVie & Approved & Oncology & Byrd et al. (2015) \\
Acalabrutinib (ACP-196) & Acerta Pharma & Phase 3 & Oncology & Byrd et al. (2016) \\
BGB-3111 & BeiGene & Phase 3 & Oncology & Tam et al. (2015) \\
Spebrutinib (CC-292) & Celgene & Phase 2 & Autoimmune & Evans et al. (2013) \\
Evobrutinib (M2951) & Merck Serono & Phase 2 & Autoimmune & Grenningloh (2016) \\
PRN-1008 & Principia & Phase 2 & Autoimmune & Smith et al. (2015) \\
LY3337641 (HM-71224) & Lilly & Phase 2 & Autoimmune & Park et al. (2016) \\
M7583 & Merck Serono & Phase 1/2 & Oncology & Bender et al. (2016) \\
Tirabrutinib (GS-4059) & Gilead & Phase 1 & Oncology & Walter et al. $(2016)$ \\
AC-0058TA & ACEA Biosciences & Phase 1 & Autoimmune & - \\
\hline
\end{tabular}

${ }^{a}$ Development stage of most advanced clinical program, based on ClinicalTrials.gov. Additional potential covalent BTK inhibitors include CT-1530, BMS-986195, and DTRMWXHS-12.

ibrutinib-mediated adverse events include rash, diarrhea, arthralgias or myalgias, atrial fibrillation, and major hemorrhage (Byrd et al., 2013; Wang et al., 2013; O'Brien et al., 2014), some of which may be explained by inhibition of offtarget kinases EGFR, TEC, ITK, and TXK (Honigberg et al., 2010). Spebrutinib is another covalent BTK inhibitor that was subject to clinical evaluation; although it was reportedly a highly selective inhibitor (Evans et al., 2013), doses needed to achieve a partial response in patients with relapsed or refractory chronic lymphocytic leukemia (CLL) or small lymphocytic lymphoma are higher than for ibrutinib (Brown et al., 2016).

Here we report the differentiated profile of BTK inhibitor acalabrutinib [compound 1, ACP-196 (1,4-[8-amino-3-[(2S)-1-but2-ynoylpyrrolidin-2-yl]imidazo[1,5-a]pyrazin-1-yl]- $N$-(2-pyridyl)benzamide)]. Acalabrutinib is a small-molecule irreversible BTK inhibitor (Fig. 1) that shows encouraging clinical activity and safety in patients with relapsed or refractory CLL (Byrd et al., 2016). The preclinical profile of acalabrutinib and a few additional compounds was compared with ibrutinib<smiles>CC#CC(=O)N1CCC[C@H]1c1nc(-c2ccc(C(=O)Nc3ccccn3)cc2)c2c(N)nccn12</smiles>

Acalabrutinib (ACP-196, 1)<smiles>C=CC(=O)N1CCC[C@H](n2nc(-c3ccc(Oc4ccccc4)cc3)c3c(N)ncnc32)C1</smiles>

Ibrutinib (PCl-32765, 2)<smiles>C=CC(=O)Nc1cccc(Nc2nc(Nc3ccc(OCCOC)cc3)ncc2F)c1</smiles>
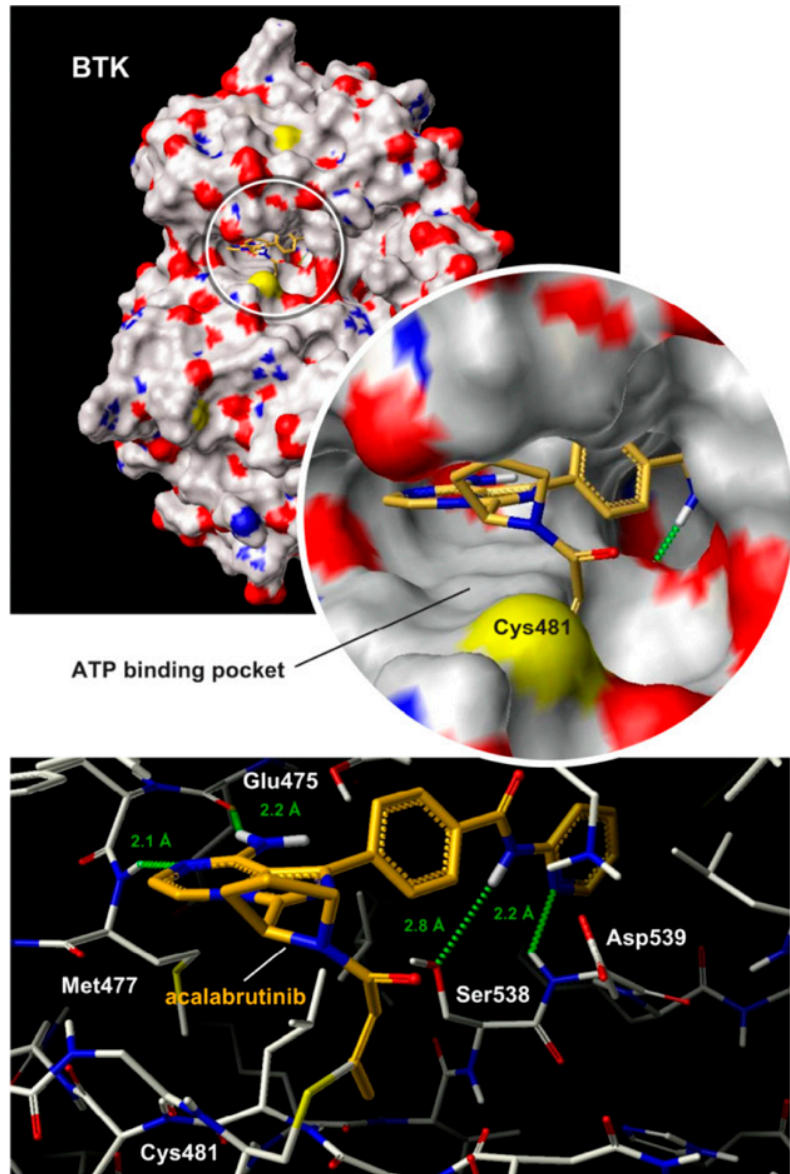

Fig. 1. (Left) Chemical structures of clinical irreversible binding BTK inhibitors. (Top right) Front view of a binding model of acalabrutinib (gold) in the ATP binding pocket of BTK. (Bottom right) Second view of the model, showing the hydrogen bonding interaction of the 2-pyridylamide moiety with Ser538 and Asp539. 
(PCI-32765, compound 2) and spebrutinib (CC-292, compound 3 ) to investigate potential differences in potency, efficacy, and selectivity, while also engaging in covalent binding. Comparative preclinical studies involved pharmacologic profiling in biochemical and functional cellular assays, as well as in a PD model in mice. BTK target occupancy was correlated with PD markers by using a potent and selective biotinylated probe that was developed based on the chemical structure of acalabrutinib. In addition, we aimed to better understand the potential risk of adverse events by investigating the impact of structure-reactivity relationships on kinase selectivity. Finally, data are presented on the $\mathrm{PK} / \mathrm{PD}$ relationships of acalabrutinib in healthy volunteers. The combined features of acalabrutinib result in a selective and potent BTK inhibitor that appears to be differentiated from ibrutinib and spebrutinib, supporting further clinical development.

\section{Materials and Methods}

Biochemical Kinase Assays. BTK and ITK enzyme activity was measured using the immobilized metal ion affinity-based fluorescence polarization (IMAP) assay. BTK enzyme (Millipore, Dundee, UK) or ITK enzyme (Millipore) was diluted to 16 and $34 \mathrm{nM}$, respectively, in kinase reaction (KR) buffer $(10 \mathrm{mM}$ Tris- $\mathrm{HCl}$, $10 \mathrm{mM} \mathrm{MgCl}_{2}, 0.01 \%$ Tween 20, $0.1 \% \mathrm{NaN}_{3}, 1 \mathrm{mM}$ dithiothreitol, and $2 \mathrm{mM} \mathrm{MnCl} 2, \mathrm{pH} 7.5$ ). Serial dilutions (log10) from $1 \mathrm{mM}$ to $31.6 \mathrm{nM}$ of test compounds were made in $100 \%$ dimethylsulfoxide (DMSO). The dilutions in DMSO were then diluted 25-fold in KR buffer. Final compound concentrations ranged from $10 \mu \mathrm{M}$ to 0.316 $\mathrm{nM}$. Test compound ( $5 \mu \mathrm{l} /$ well) in KR buffer (final DMSO concentration of $1 \%$ ) was mixed with $5 \mu \mathrm{l} /$ well BTK or ITK enzyme (final concentration of 4 and $8 \mathrm{nM}$ for BTK and ITK, respectively). Test compounds and kinase enzyme were preincubated 1 hour at room temperature before the addition of $5 \mu \mathrm{l} /$ well of $200 \mathrm{nM}$ fluoresceinlabeled substrate peptide (Blk/Lyntide substrate; Molecular Devices, Sunnyvale, CA) in KR buffer. The final peptide substrate concentration was $50 \mathrm{nM}$. The kinase assay was started by adding $5 \mu \mathrm{l} /$ well of $20 \mu \mathrm{M}$ ATP in KR buffer (final ATP concentration of $5 \mu \mathrm{M}$ ATP, $K_{\mathrm{m}}$ ATP). After incubation for 2 hours at room temperature, the enzyme reaction was stopped by adding $40 \mu \mathrm{l} /$ well IMAP Progressive Binding Solution (Molecular Devices), according to the manufacturer's instructions, using 60\% $1 \times$ buffer $\mathrm{A}$ and $40 \% 1 \times$ buffer B with $800 \times$ diluted beads. After 60 -minute incubation at room temperature in the dark, the fluorescence polarization signal was read. Fluorescence at $535 \mathrm{~nm}$ was measured using parallel and perpendicular filters to determine differences in rotation due to binding of the phosphorylated substrate peptide to the beads. Values were calculated as the percentage of the difference in readout (delta millipolarization) of the controls with and without ATP. IC $_{50}$ values were determined by curve fitting of the experimental results using Dotmatics software (Dotmatics, Bishop's Stortford, UK).

Inhibitory activity on TEC was measured using the LanthaScreen assay (Thermo Fisher Scientific, Carlsbad, CA) according the manufacturer's protocol, with a final concentration of $1 \mathrm{nM}$ TEC enzyme (Life Technologies, Carlsbad, CA) and $2 \mathrm{nM}$ Eu-anti-His antibody (Invitrogen, Carlsbad, CA). Serial dilutions of test compounds were prepared as described above for the BTK and ITK IMAP assays. Test compounds, TEC enzyme/antibody mix, and Tracer 178 (final concentration of $1 \mathrm{nM}$; Invitrogen) were mixed and incubated for 2 hours at room temperature in the dark, prior to reading the time-resolved fluorescence energy transfer signal at 615 and $665 \mathrm{~nm}$. A ratio of $665 / 615$ was used to calculate values expressed as the percentage of the difference in readout $(\mathrm{S} / \mathrm{N})$ of the controls with and without the tracer. $\mathrm{IC}_{50}$ values were determined by curve fitting of the experimental results using Dotmatics. Kinase activity was measured using the $\mathrm{Z}^{\prime}$-LYTE assay (Thermo Fisher Scientific) for the following: BMX, TXK, EGFR, ERBB2, ERBB4, JAK3, BLK, FGR, FYN,
HCK, LCK, LYN, SRC, and YES1. A 10-point dose response was generated with 1 hour incubation of the test compound with the kinase prior to initiation of the kinase reaction by the addition of ATP. The ATP concentration in the assay was $K_{\mathrm{m}}$ ATP for the different kinases. $\mathrm{IC}_{50}$ values were determined by curve fitting of the experimental results at Thermo Fisher.

Glutathione Reactivity Assay. For this assay, $765 \mu \mathrm{l}$ of a $3.32 \mathrm{mM}$ solution of test compound in methanol was added to $765 \mu \mathrm{l}$ of a $23.5 \mathrm{mM}$ solution of reduced L-glutathione (GSH) in phosphate buffer ( $\mathrm{pH}$ 7.4). The mixtures were stirred in a water bath held at $37^{\circ} \mathrm{C}$. At specific time intervals, $200-\mu \mathrm{l}$ aliquots were taken and analyzed by reversed-phase high-performance liquid chromatography (Supplemental). Ln([compound]/[compound]0) was plotted against the time in minutes and linear regression analysis was performed with Excel (Microsoft, Redmond, WA). The time point at which $50 \%$ of the compound was consumed via reaction with GSH (terminal elimination half-life; $\left.t_{1 / 2}\right)$ was calculated as $t_{1 / 2}=\operatorname{Ln}(2) / k$, where $k$ is the negative of the slope of the linear trend line.

Human Blood Collection and Human Peripheral Blood Mononuclear Cell Isolation. Venous blood was collected in heparin tubes from healthy human volunteers and kept at ambient temperature for no longer than 24 hours. Peripheral blood mononuclear cells (PBMCs) were isolated, this was done using the Histopaque gradient purification method (GE Healthcare, Uppsala, Sweden) and cryopreserved in $90 \%$ DMSO plus $10 \%$ fetal bovine serum (FBS).

Inhibition of BCR-Induced CD69 Surface Expression in Human B Cells: PBMC Assay. Cryopreserved PBMCs were thawed, washed, and suspended at $2 \times 10^{5}$ cells/well in RPMI plus $10 \%$ FBS in 96 -well plates. Test compounds were added to PBMCs using a $1 / 2 \log$ dose titration (final concentration of $10 \mu \mathrm{M}$ to $0.316 \mathrm{nM}$ ) and incubated for 2 hours at $37^{\circ} \mathrm{C}, 5 \% \mathrm{CO}_{2}$. The final DMSO concentration was $0.1 \%$. Goat anti-human immunoglobin IgM $\mathrm{F}\left(\mathrm{ab}^{\prime}\right) 2$ (Southern Biotech, Birmingham, AL) was added and cells were incubated for an additional 18 hours. Cells were stained with CD69-fluorescein isothiocyanate (FITC), CD19-BV421, and CD3-BV510 antibodies (BD Biosciences, San Diego, CA) for 30 minutes at $4^{\circ} \mathrm{C}$, with 7 -aminoactinomycin $\mathrm{D}(7-\mathrm{AAD})$ as a viability measure, followed by flow cytometry using a FACSVerse flow cytometer (BD Biosciences).

Inhibition of BCR-Induced CD69 Surface Expression in Human B cells: Whole blood (WB) Assay. $45 \mu \mathrm{l}$ blood was diluted 1:1 in RPMI plus 1\% FBS and incubated with test compound (as described above). Blood was stimulated with $10 \mu \mathrm{g} / \mathrm{ml}$ mouse antihuman anti-IgD (BD Biosciences) and incubated for 18 hours. Cells were stained with CD69-FITC, CD19-BV421, and CD3-BV510 (BD Biosciences) for 15 minutes at room temperature, followed by red blood cell lysis with FACS lysing solution (BD Biosciences) in a 96-deep-well plate. Cells were washed with $1 \mathrm{ml} /$ well PBS plus $0.5 \%$ bovine serum albumin (BSA), pelleted, and resuspended in $200 \mu \mathrm{l} /$ well PBS plus $0.5 \%$ BSA, followed by flow cytometry. For both PBMC and WB assays, median fluorescence intensity values for CD69 were obtained from the CD19+ CD3- B lymphocyte gate using FCSExpress analysis software (De Novo Software, Glendale, CA). $\mathrm{EC}_{50}$ values were determined by curve fitting of the experimental results using Dotmatics.

Murine PD Model. Balb/c mice were dosed via oral gavage with inhibitors or vehicle and then euthanized after 1-24 hours. Extracted spleens were disassociated to obtain single-cell suspensions. Red blood cells were lysed with an ammonium chloride solution (Sigma-Aldrich, Zwijndrecht, the Netherlands). The remaining cells were washed with cold PBS and counted. An aliquot of $1 \times 10^{6}$ cells was snap frozen $\left(\mathrm{LN}_{2}\right)$ as cell pellets for subsequent BTK target occupancy enzyme-linked immunosorbent assay (ELISA) and the remainder was used for CD69 analysis (see below).

BTK Target Occupancy ELISA. The percentage of drug-bound BTK in mouse and human samples was determined by an ELISAbased method as follows: OptiPlate 96-well plates (PerkinElmer, Waltham, MA) were coated with $125 \mathrm{ng} /$ well anti-BTK antibody 
(BD Biosciences) and blocked with BSA (Sigma-Aldrich). Samples containing either $5 \times 10^{5}$ or $1 \times 10^{6}$ cells from human PBMCs or mouse splenocytes, respectively, were lysed in ice-cold lysis buffer containing $50 \mathrm{mM}$ Tris- $\mathrm{HCl}$, pH 7.5, $250 \mathrm{mM}$ sucrose, $5 \mathrm{mM} \mathrm{MgCl}_{2}$, $1 \mathrm{mM}$ dithiothreitol, $0.05 \%$ digitonin, and protease inhibitor cocktail (Sigma-Aldrich). Cell lysates were then incubated for 1 hour in the absence or presence of $1 \mu \mathrm{M}$ acalabrutinib, a saturating concentration that results in complete BTK occupancy. The difference of the signal with excess acalabrutinib represents free BTK. Samples were incubated for 1 hour with $100 \mathrm{nM}$ biotin tag compound ACP-4016 (compound 10; Fig. 4D). This probe will bind covalently to Cys481 in the ATP pocket in BTK when the ATP pocket is not occupied by a covalent BTK inhibitor. Each sample was then added in duplicate to the prepared OptiPlate and incubated for 2 hours at ambient temperature. Plates were washed with PBS plus $0.05 \%$ Tween 20 four times. Streptavidin-horseradish peroxidase (Invitrogen; ELISA grade) was added at $100 \mu \mathrm{l} / \mathrm{well}(120 \mathrm{ng} / \mathrm{ml})$ and incubated for 1 hour at room temperature. Plates were washed with PBS plus $0.05 \%$ Tween 20 three times and then washed with PBS (without Tween 20) two times. SuperSignal ELISA Femto Substrate (100 $\mu \mathrm{l} /$ well; Thermo Fisher Scientific) was added and then chemiluminescence was measured after 1 minute (EnVision plate reader; PerkinElmer). The percentage of BTK occupancy for each sample time point was calculated relative to the day 1 predose sample for each patient. The signal from the day 1 predose sample without exogenous acalabrutinib represents $100 \%$ free BTK (or $0 \%$ occupied BTK), whereas the signal from the day 1 predose sample with exogenous acalabrutinib represents 0\% free BTK (or 100\% occupied BTK). The incubation of each cell lysate with $1 \mu \mathrm{M}$ acalabrutinib was used to correct for background signal not related to free BTK as follows:

$$
\begin{aligned}
\% \text { Free BTK Sample } X= & \left(\text { Sample } X-\text { Sample } X^{+\operatorname{drug}[1 \mu M]}\right) / \\
& \left(\text { Day } 1 \text { Predose }- \text { Day } 1 \text { Predose }^{+ \text {drug }[1 \mu M]}\right) \\
& \times 100 \%
\end{aligned}
$$$$
\% \text { Occupied BTK }=100 \%-\% \text { Free BTK }
$$

Ex Vivo BCR-Induced CD69 Expression in Mouse B Cells. Splenocytes from drug- and vehicle-treated mice were plated at $2 \times 10^{5}$ cells/well in 96 -well flat-bottom plates. Goat anti-mouse IgM $(10 \mu \mathrm{g} / \mathrm{ml}$; Southern Biotech) was added and cultures were incubated for 18 hours at $37^{\circ} \mathrm{C}, 5 \% \mathrm{CO}_{2}$. Cells were treated with Fc Block (BD Biosciences) and were subsequently stained with CD69-FITC, CD19-BV421, CD3-BV510 (BD Biosciences), and 7-AAD, followed by flow cytometry. Median fluorescent intensity values for CD69 were obtained from the B lymphocyte gate (CD19+, CD3-). Values were normalized to a percentage of the control, with the control being the CD69 median fluorescent intensity from the vehicle-treated mice for each time point. Cells without anti-IgM addition served to define the basal expression.

EGFR Inhibition. A431 cells were plated at $4 \times 10^{4}$ cells/well in a 96-well culture plate (MicroWell 96-well microplates; Nunc, Roskilde, Denmark) in Dulbecco's modified Eagle's medium/HAM F12 plus $10 \% \mathrm{FBS}$ and incubated overnight at $37^{\circ} \mathrm{C}, 5 \%-7 \% \mathrm{CO}_{2}$. Serial dilutions (1/2 log) of test compounds were made in $100 \%$ DMSO, added to the $\mathrm{A} 431$ cells (final compound concentration range, $10 \mu \mathrm{M}$ to $0.316 \mathrm{nM}$; final concentration of $1 \% \mathrm{DMSO}$ ), and incubated with the cells for 2 hours at $37^{\circ} \mathrm{C}, 5 \%-7 \% \mathrm{CO}_{2}$, followed by a 10 -minute stimulation with epidermal growth factor (EGF) (final concentration of $250 \mathrm{ng} / \mathrm{ml}$; Tebu-bio BV, Rocky Hill, NJ). Culture medium was removed from the cells and $100 \mu \mathrm{l} /$ well lysis buffer (cell extraction buffer, Invitrogen plus protease inhibitor cocktail; Roche, Indianapolis, IN) was added. Cell lysates were used to measure phospho-EGFR ELISA (DuoSet IC, human phospho-EGFR/ERBB1; R\&D Systems, Minneapolis, $\mathrm{MN})$. $\mathrm{EC}_{50}$ values were determined by curve fitting of the experimental results using Dotmatics software.
Jurkat T Cell Assay. Regulation of anti-CD3/CD28-induced interleukin (IL)-2 production on Jurkat T cells was performed using a clone obtained by dilution cloning, with high expression of IL-2 after stimulation (Jurkat J.E6.2.11). Jurkat cells were plated at $2 \times 10^{5}$ cells/well in a 96-well culture plate (MicroWell 96-well microplates; Nunc) cultured in Dulbecco's modified Eagle's medium F12 plus $10 \%$ FBS and then cultured overnight in a cell culture incubator, $37^{\circ}$, $5 \%-7 \% \mathrm{CO}_{2}$. Serial dilutions ( $\left.1 / 2 \mathrm{log}\right)$ of test compounds were made in $100 \%$ DMSO and added to the Jurkat cells (final compound concentration range, $10 \mu \mathrm{M}$ to $0.316 \mathrm{nM}$; final concentration of $0.1 \% \mathrm{DMSO}$ ). After 1-hour incubation, Jurkat cells were stimulated with antihuman CD3 and anti-human CD28 $(0.1 \mu \mathrm{g} / \mathrm{ml}$ final concentration in the assay; BD Biosciences). The cell culture medium was harvested after 6-hour incubation after activation and was used subsequently to measure IL-2 produced by ELISA (human IL-2 CytoSets; BioSource, Frederick, MD). EC $_{50}$ values were determined by curve fitting of the experimental results using Dotmatics software.

Human PBMC T Cell Assay. Cryopreserved PBMCs were thawed, washed, and suspended at $1 \times 10^{5}$ cells/well in RPMI plus $10 \%$ FBS in 96-well U-bottom polypropylene plates and rested for 1 hour at $37^{\circ} \mathrm{C}, 5 \%$ $\mathrm{CO}_{2}$. Cells were then pretreated with a 10-point serial dilution of compounds (as described above for B cell assays). Preincubated PBMCs were transferred to 96 -well round-bottom polystyrene plates coated with anti-human CD3 antibody (coated at $10 \mu \mathrm{g} / \mathrm{ml}$ for 2 hours at $37^{\circ} \mathrm{C}$, clone UCHT-1; BD Biosciences) or in uncoated wells for controls and incubated overnight at $37^{\circ} \mathrm{C}, 5 \% \mathrm{CO}_{2}$. PBMCs were washed twice in PBS containing 0.5\% BSA and stained with CD4-Alexa Fluor 647 (clone RPA-T4) and CD8-Alexa Fluor 647 (clone RPA-T8; BD Biosciences), CD19-BV421 (clone HIB19), CD69-FITC (clone FN50; BD Biosciences), and CD25-PE-Cy7 antibodies (BD Biosciences) for 30 minutes at $4^{\circ} \mathrm{C}$ in the dark. After the cells were washed twice in PBS plus 0.5\% BSA, 7-AAD (Life Technologies) was added and cells were analyzed on a FACSVerse flow cytometer (BD Biosciences). The percentages of CD25 + T cells within viable CD4+CD8+CD19- T cells were determined using FCS Express software (DeNovo Software, Glendale, $\mathrm{CA}$ ). $\mathrm{EC}_{50}$ values were determined by curve fitting of the experimental results using Dotmatics software.

PK of Healthy Volunteers. Acalabrutinib was tested in an escalating-dose, safety, and PK/PD study in healthy adult volunteers. Two oral doses of 2.5, 5, 25, and $50 \mathrm{mg}$ were administered 12 hours apart on a single day or as a single dose of 75 or $100 \mathrm{mg}$ (study ACEHV-001). The study was performed in accordance with the ethical principles stated in the Declaration of Helsinki, U.S. Food and Drug Administration regulation 21 CFR 312 (parts 50 and 56), and International Conference on Harmonisation guidelines for good clinical practice. All subjects provided informed consent on an institutional review board-approved protocol. Acalabrutinib was administered after an overnight fast and blood samples were collected for PK analysis at predose and at 15 and 30 minutes and 1, 1.5, 2, 3, 4, 6, 8, $12,13,14,15,16,18,20,24,36,48$, and 60 hours postdose ( \pm 5 minutes). Plasma concentrations of acalabrutinib were determined using a validated analytical liquid chromatography-tandem mass spectrometry method against a stable labeled internal standard at Basi (West Lafayette, IN) in lithium heparin plasma. The quantification range for acalabrutinib was $1-1000 \mathrm{ng} / \mathrm{ml}$.

PK analyses were performed using noncompartmental methods with Phoenix WinNonlin (version 6.3; Pharsight Inc., Mountain View, CA) and GraphPad Prism (version 6.00 for Windows; GraphPad Software Inc., La Jolla, CA) software. The maximum observed plasma concentration $\left(C_{\max }\right)$ and time to reach $C_{\max }\left(T_{\max }\right)$ were taken directly from the individual's data. The following PK parameters were derived from the plasma concentrations of acalabrutinib: area under the concentration-time curve (AUC) from time 0 to last quantifiable concentration $\left(\mathrm{AUC}_{0-\text { last }}\right), \mathrm{AUC}$ from time 0 to $\infty\left(\mathrm{AUC}_{0-\infty}\right), C_{\max }$, $T_{\max }, t_{1 / 2}$, and terminal elimination rate constant $(\lambda \mathrm{z}) . \mathrm{AUC}_{0-12}$, $\mathrm{AUC}_{0-24}$, and $\mathrm{AUC}_{0-\infty}$ (where data permitted) were calculated using the linear trapezoidal method (log/linear rule). As data permitted, $\lambda z$ 


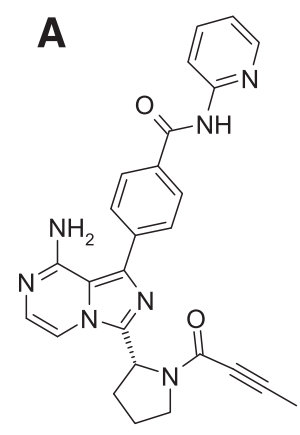

(4)<smiles>[R1]c1ccc(-c2nc(C3CCCN3C(=O)C#CC)n3ccnc(N)c23)cc1</smiles><smiles>[R2]N1CCC[C@H]1c1nc(-c2ccc(C(=O)Nc3ccccc3)cc2)c2c(N)nccn12</smiles>

R2:<smiles>C=CC(C)=O</smiles>

(7)

B<smiles>CC=CC(C)=O</smiles>

(8)

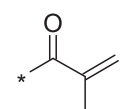

(9)

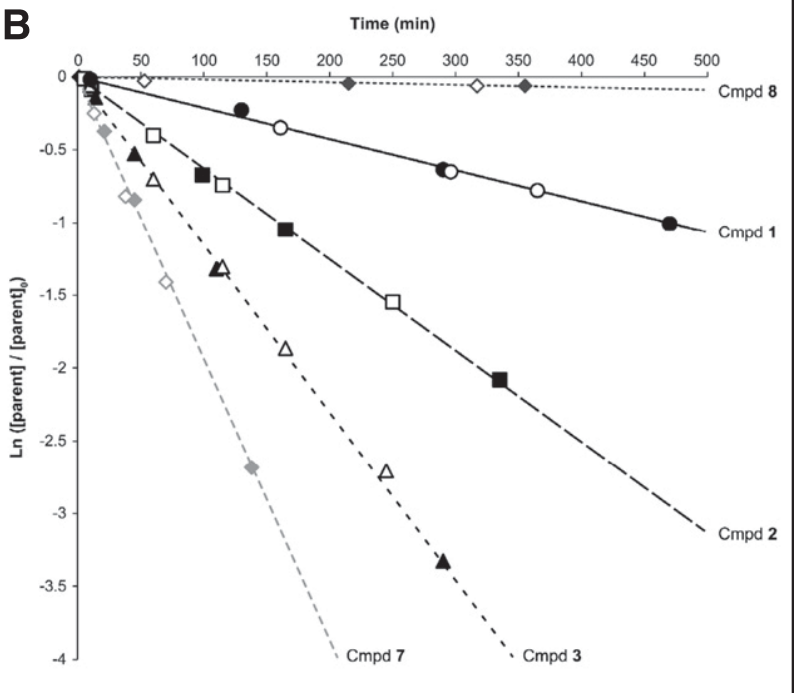

(6)

Fig. 2. (A) Chemical structures of compounds 4-9. (B) Average $t_{1 / 2}$ determination in a pseudo-first-order GSH reactivity assay. In brief, the compounds were incubated with an excess of GSH at $37^{\circ} \mathrm{C}, \mathrm{pH} 7.4$, in a buffered aqueous methanol mixture. Consumption of the electrophilic parent compound was monitored via reversed-phase high-performance liquid chromatography, and the $t_{1 / 2}$ (50\% of parent consumed) was determined based on linear regression analysis from two independent experiments. The table shows biochemical IMAP and cell-based data for compounds 1-9 and GSH reactivity data for selected compounds. Cmpd, compound.

was calculated as the negative of the slope of the terminal log-linear segment of the plasma concentration-time curve. $t_{1 / 2}$ was calculated according to the following equation: $t_{1 / 2}=0.693 / \lambda \mathrm{z}$. Oral clearance $(\mathrm{CL} / \mathrm{F})$ and volume of distribution $(\mathrm{Vz} / \mathrm{F})$ were calculated as follows: $\mathrm{CL} / \mathrm{F}=\left(\operatorname{dose} / \mathrm{AUC}_{\infty}\right)$ and $\mathrm{Vz} / \mathrm{F}=$ Dose $/ \lambda \mathrm{z} \cdot \mathrm{AUC}_{\infty}$.

\section{Results}

On-Target Biochemical and Functional Characterization and Modeling of BTK Inhibitor Interactions. Acalabrutinib (compound 1) displayed low nanomolar inhibition in the IMAP assay with an $\mathrm{IC}_{50}$ value of $5.1 \mathrm{nM}$. In a headto-head comparison in the same biochemical assay, ibrutinib (compound 2) had a potency (as measured by $\mathrm{IC}_{50}$ ) of $1.5 \mathrm{nM}$, whereas the potency of spebrutinib (compound 3) was $2.3 \mathrm{nM}$ (Fig. 2). However, the inhibitory potential of spebrutinib was lower in BCR-mediated cell surface expression of CD69 in PBMCs and in the human whole blood (hWB) assay. In the latter assay, acalabrutinib $\left(\mathrm{EC}_{50}=9.2 \pm 4.4 \mathrm{nM}\right)$ and ibrutinib $\left(\mathrm{EC}_{50}=5.8 \pm 3.0 \mathrm{nM}\right)$ showed no statistically significant difference, whereas spebrutinib was less potent $\left(\mathrm{EC}_{50}=140 \mathrm{nM}\right)$. Inversion of the stereochemistry of acalabrutinib had a profound effect on the inhibitory potency of BTK, as demonstrated by the approximately 130 -fold loss in the IMAP assay. The cell-based $\mathrm{EC}_{50}$ values of the $R$-enantiomer (compound 4) were consistent with this observation as well (592 and $1530 \mathrm{nM}$ in the PBMC and hWB assays, respectively). 
Figure 1 shows a model of the acalabrutinib/BTK complex that was created by docking acalabrutinib into the ATP pocket of BTK using a cocrystal structure of a reversible inhibitor/BTK complex (Protein Data Bank entry 3GEN). The model included minimization of two amino acid residues to accommodate the back-pocket filling substituent of acalabrutinib (Met449 and Leu542). This model indicates that H-bonding capabilities of the central 8-aminoimidazopyrazine moiety with Met477 and Glu475 in the hinge region are present. The 2-pyridylbenzamide shows hydrogen bonding interactions with Ser538 and Asp539.

The importance of the 2-pyridyl nitrogen was further elucidated by profiling compounds in which the 2-pyridyl nitrogen is moved to positions 3 and 4, respectively. Compounds containing 3-pyridyl (compound 5) and 4-pyridyl (compound 6) moieties were 840- and 360-fold less potent than acalabrutinib in the biochemical assay. Absence of activity was confirmed in peripheral $\mathrm{B}$ cells in functional assays using human PBMCs and hWB, with $\mathrm{EC}_{50}>4 \mu \mathrm{M}$ for both compounds (Fig. 2). Data generated on additional compounds highlight the relevance of the positioning of the H-bonding partners when the amide as the linker is employed (Supplemental Table 1).

We also explored the impact of (un)substituted acrylamide functions as in compounds 7, 8, and 9. Unsubstituted acrylamide compound 7 was generally 3 -fold more potent in the biochemical and cell-based assays compared with acalabrutinib. However, the introduction of a methyl group on the $\beta$ (as in compound 8) or $\alpha$ position (compound 9) of the acrylamide reduced the biochemical and cell-based potency by $\geq 100$ and $\geq 900$-fold, respectively. To demonstrate the relative contribution of affinity and inactivation rate, $K_{\mathrm{I}}$ and $k_{\text {inact }}$ values were determined for compounds 1, 2, 3, and 7 (Supplemental Table 2). The higher potency of acrylamide compound 7 compared with acalabrutinib seems to depend primarily on a faster inactivation rate $\left(k_{\text {inact }}\right)$, as the affinity $\left(K_{\mathrm{I}}\right)$ was relatively similar. For ibrutinib, the affinity component appears to be a relative important contributor to the observed potency.

Glutathione Thiol Reactivity and Kinase Selectivity. The microenvironment of Cys481 in BTK has been reported to augment the nucleophilicity of the cysteine compared with some other cysteine-containing kinases. This presents an opportunity to improve (i.e., reduce) the electrophilicity of covalent binding BTK inhibitors. The $\mathrm{p} K_{\mathrm{a}}$ of the cysteine sulfhydryl group is directly influenced by proximal amino acids (Kortemme and Creighton, 1995; Garske et al., 2011). All TEC kinases, except ITK, contain an asparagine (Asn) residue at the $i+3$ position with respect to the reactive cysteine, and this results in a reported $\mathrm{p} K_{\mathrm{a}}$ of approximately 7.7 for Cys 481 in BTK (Zapf et al., 2012). Intriguingly, the other cysteinecontaining kinases such as EGFR, ERBB2, BLK, and JAK3 have an aspartate (Asp) in this position, which has been suggested to increase the $\mathrm{p} K_{\mathrm{a}}$ and thus lower the nucleophilicity of the sulfhydryl group. Current data suggest that the thiol $\mathrm{p} K_{\mathrm{a}}$ increases by about 0.6-1.3 log units for the Aspcontaining kinases (Supplemental Table 3). Lower intrinsic electrophilicity of a covalent inhibitor appears to reduce the likelihood of covalent binding to off-target cysteines with a lower nucleophilicity and favorably affects kinase selectivity within the kinase subset with an Asp in the $i+3$ position while preserving potency for BTK.

To further substantiate whether the relative reactivity of the electrophilic moieties could impact the BTK potency and
TABLE 2

$\mathrm{IC}_{50}$ determination on cysteine kinases with a cysteine in the same position as Cys481 in BTK

\begin{tabular}{|c|c|c|c|c|c|}
\hline \multirow{2}{*}{ Kinase } & \multirow{2}{*}{ i+3 Residue } & \multicolumn{4}{|c|}{$\mathrm{IC}_{50}$} \\
\hline & & 1 & 2 & 3 & 7 \\
\hline & & \multicolumn{4}{|c|}{$n M$} \\
\hline BTK & Asn & $5.1 \pm 1.0$ & $1.5 \pm 0.2$ & $2.3 \pm 0.5$ & $1.6 \pm 0.2$ \\
\hline TEC & Asn & $126 \pm 11$ & $10 \pm 2$ & $16 \pm 4$ & $41 \pm 3$ \\
\hline ITK & Asp & $>1000$ & $4.9 \pm 1.2$ & $24 \pm 2$ & $52 \pm 5$ \\
\hline BMX & Asn & $46 \pm 12$ & $0.8 \pm 0.1$ & $1.6 \pm 0.4$ & $3.3 \pm 0.4$ \\
\hline TXK & Asn & $368 \pm 141$ & $2.0 \pm 0.3$ & $9.1 \pm 2.7$ & $7.6 \pm 2.4$ \\
\hline EGFR & Asp & $>1000$ & $5.3 \pm 1.3$ & $199 \pm 35$ & $20 \pm 5$ \\
\hline ERBB2 & Asp & $\sim 1000$ & $6.4 \pm 1.8$ & $>1000$ & $13 \pm 3$ \\
\hline ERBB4 & Glu & $16 \pm 5$ & $3.4 \pm 1.4$ & $49 \pm 12$ & $5.3 \pm 0.5$ \\
\hline BLK & Asp & $>1000$ & $0.1 \pm 0.0$ & $131 \pm 27$ & $19 \pm 4$ \\
\hline JAK3 & Asp & $>1000$ & $32 \pm 15$ & $5.4 \pm 1.1$ & $>1000$ \\
\hline
\end{tabular}

BTK and ITK kinase activity was measured using the IMAP assay. For BMX, TXK, EGFR, ERBB2, ERBB4, BLK, and JAK3, kinase activity was measured at Thermo Fisher using the Z'-LYTE assay. TEC kinase activity was determined in a LanthaScreen assay. Results are mean \pm S.D. of at least three independent experiments.

the overall kinase selectivity profile, the inhibitors were reacted with GSH in a semiphysiologic setting. Acalabrutinib has a butynamide moiety, which contributes to a slower conversion of the parent, with a $t_{1 / 2}$ of 5.5 hours (Fig. 2). In contrast, the acrylamide-containing compounds ibrutinib and spebrutinib were more rapidly consumed than acalabrutinib, with average $t_{1 / 2}$ values of 2 and 1 hours, respectively. Intriguingly, compound 7 displayed a much faster turnover than acrylamides ibrutinib and spebrutinib. The closer proximity of the electrophile in compound 7 to the electron-deficient central heteroaryl imidazopyrazine moiety could augment the electrophilicity and may explain the lower $t_{1 / 2}$ average of 0.6 hours. Methyl compounds 8 and 9 lose the capacity to react with GSH, which suggests that the degree of BTK inhibition observed could be due to reversible binding (Fig. 2). The observation that compound 8 still displayed some residual activity suggests that steric hindrance in proximity of Cys481 impacts the binding potential, rather than the relative electrophilicity of the reactive group per se.

Profiling of the clinical BTK inhibitors and compound 7 on the cysteine kinase panel distinguishes acalabrutinib from the acrylamide compounds in terms of selectivity. All kinases with an Asp in the $i+3$ position were not sensitive to acalabrutinib, and the inhibition of TEC, BMX, and TXK kinases was lower than for any of the acrylamide compounds. A direct comparison of the $\mathrm{IC}_{50}$ values of acalabrutinib and acrylamide-containing compound 7 revealed the influence of the warhead choice on the cysteine kinase selectivity profile (Table 2). In this data set, ERBB4 is an outlier, as this is the only kinase that has a glutamate (Glu) in the $\mathrm{i}+3$ position. Although the predicted cysteine $\mathrm{p} K_{\mathrm{a}}$ is on par with Asp kinases, the tested compounds acalabrutinib, ibrutinib, spebrutinib, and acrylamide compound 7 all displayed a single- or double-digit nanomolar inhibition in the biochemical assay for ERBB4. Since spebrutinib was comparatively fairly reactive, yet the least potent on ERBB4 $\left(\mathrm{IC}_{50}=49 \mathrm{nM}\right)$, the inhibition of ERBB4 may be governed to a lesser extent by the electrophilic nature of the reactive moiety. Each of the clinical BTK inhibitors was also profiled at $1 \mu \mathrm{M}$ in a competition binding assay on a panel of 456 human kinases (KINOMEscan at 

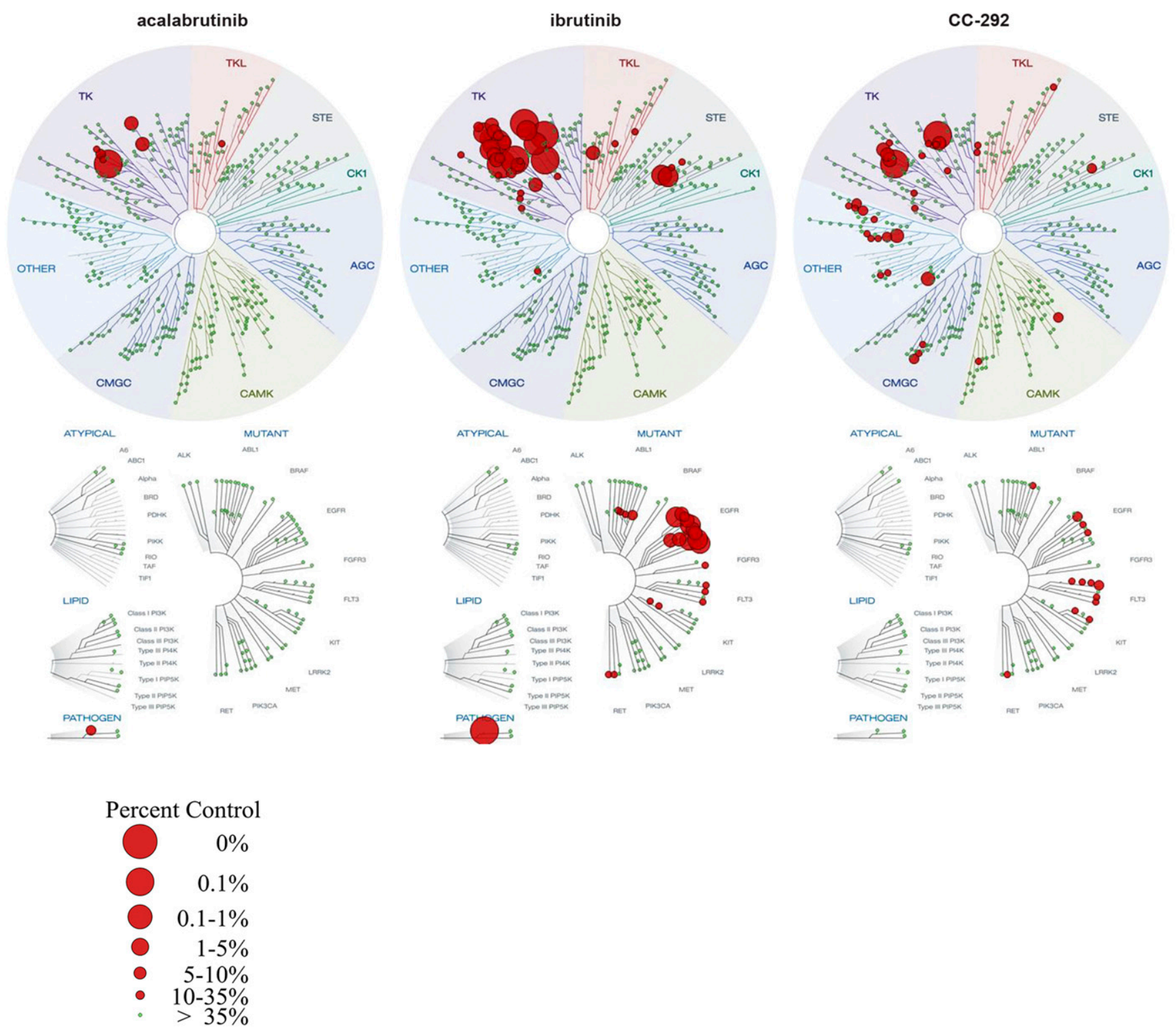

Fig. 3. Comparison of acalabrutinib, ibrutinib, and spebrutinib in competitive binding assays on wild-type and mutant kinases (DiscoverX). Compounds were tested at a single concentration of $1 \mu \mathrm{M}$. Data are expressed as the percentage of remaining activity versus control. The size of the circles represents intervals of the percentage of remaining activity versus the untreated control. Data presented are expansions from Herman et al. (2017).

DiscoverX, Fremont, CA). Of these kinases, 395 are nonmutant protein kinases. Our results demonstrate that acalabrutinib is the most selective BTK inhibitor of the three compounds profiled (Fig. 3). For acalabrutinib, only $1.5 \%$ of the nonmutant protein kinases were inhibited $\geq 65 \%$ at $1 \mu \mathrm{M}$. For ibrutinib and spebrutinib, 8.9\% and 7.6\%, respectively, of the nonmutant protein kinases were inhibited $\geq 65 \%$ at $1 \mu \mathrm{M}$. Interestingly, strong inhibition by ibrutinib was observed for all kinases belonging to the SRC-family kinases, which is in line with earlier published results (Honigberg et al., 2010) and our own data (Byrd et al., 2016). Spebrutinib showed a more scattered inhibition over the kinase phylogenetic tree. Evaluation of SRC-family kinase inhibition confirmed that acalabrutinib did not inhibit any member $\left(\mathrm{IC}_{50}\right.$ values all exceeding $1 \mu \mathrm{M}$ ), whereas ibrutinib demonstrated single- or double-digit nanomolar inhibition on all members tested (Supplemental Table 4).
Off-Target Cellular Activities of BTK Inhibitors. The functional relevance of the differences in the observed biochemical inhibition of non-BTK kinases by acalabrutinib, ibrutinib, spebrutinib, and compound 7 was explored in specific cell lines. EGFR inhibition of selected BTK inhibitors was tested in two EGFR-expressing human tumor cell lines: an epidermoid carcinoma (A431) cell line (Table 3) and a bladder carcinoma (HT-1376) cell line (Supplemental Fig. 1). Both cell lines gave similar $\mathrm{EC}_{50}$ values for the tested compounds on EGF-induced EGFR phosphorylation. Acalabrutinib showed no or only minimal inhibition up to a concentration of $10 \mu \mathrm{M}$. Results with compound 7 suggest that this is due to the electrophile switch from acrylamide to butynamide. Spebrutinib inhibited EGF-induced EGFR phosphorylation with an $\mathrm{EC}_{50}$ of $4.7 \mu \mathrm{M}$, which suggests that the reactivity of electrophile is not the only parameter relevant for kinase selectivity. Ibrutinib inhibited 
TABLE 3

Effect of selected compounds on A431 cells, Jurkat cells, and human PBMCs

\begin{tabular}{lccc}
\hline & \multicolumn{3}{c}{ EC $_{50}$} \\
\cline { 2 - 4 } Compound & $\begin{array}{c}\text { EGF-Induced EGFR } \\
\begin{array}{c}\text { Phosphorylation } \\
\text { in A431 Cells }\end{array}\end{array}$ & $\begin{array}{c}\text { Anti-CD3/CD28-Induced } \\
\text { IL-2 Production in Jurkat } \\
\text { Cells }^{b}\end{array}$ & $\begin{array}{c}\text { Anti- } \\
\text { CD3-Induced } \\
\text { CD25 Expression } \\
\text { in PBMCs }\end{array}$ \\
\hline & & $n M$ & \\
1 & $>10,000$ & $>10,000$ & $>10,000$ \\
2 & $71 \pm 14$ & $99 \pm 17$ & $257 \pm 71$ \\
3 & $4680 \pm 720$ & $150 \pm 22$ & $575 \pm 60$ \\
7 & $327 \pm 2$ & $911 \pm 61$ & $2660 \pm 956$ \\
\hline
\end{tabular}

${ }^{a}$ Results are the mean \pm error of two independent experiments.

${ }^{b}$ Results are the mean \pm S.D. of three independent experiments.

EGF-induced EGFR phosphorylation in A431 cells, with an $\mathrm{EC}_{50}$ of $71 \mathrm{nM}$.

The compounds were also evaluated in T cell functional assays. First, the compounds were profiled in anti-CD3/CD28-induced IL-2 production in Jurkat T cells, using a Jurkat E6 T cell clone with high IL-2 expression after stimulation. Ibrutinib and spebrutinib showed inhibition of anti-CD3/anti-CD28-induced IL-2 production, with $\mathrm{EC}_{50}$ values of 99 and $150 \mathrm{nM}$, respectively (Table 3). Also in line with the biochemical data on ITK, compound 7 was less potent in the Jurkat T cell assay than ibrutinib and spebrutinib. Acalabrutinib displayed an $\mathrm{EC}_{50}>10 \mu \mathrm{M}$ in the Jurkat $\mathrm{T}$ cell assay, which is expected given its biochemical selectivity over T cell kinases ITK and TXK. In addition, effects in PBMCs were studied by measuring the inhibition of anti-CD3-induced CD25 cell surface expression on human peripheral $\mathrm{T}$ cells. The order of inhibitory potential of the tested compounds followed the ranking as determined in Jurkat cells, with ibrutinib being the most potent $\left(\mathrm{EC}_{50}=257 \mathrm{nM}\right)$ and acalabrutinib being the least potent $\left(\mathrm{EC}_{50}>10 \mu \mathrm{M}\right)$ (Table 3).

Preclinical PD Model in Mice. To investigate potency in vivo, mice were treated with oral doses ranging from 0.1 to $30 \mathrm{mg} / \mathrm{kg}$ acalabrutinib, ibrutinib, or spebrutinib or with vehicle. Three hours after dosing, spleens were extracted and single-cell suspensions of splenocytes were prepared. The splenocytes were stimulated with anti-IgM for $18 \mathrm{~h}$, followed by analysis of CD69 expression by flow cytometry gated on CD19+ B cells (Fig. 4). $\mathrm{ED}_{50}$ determinations showed that acalabrutinib was the most potent BTK inhibitor in vivo $(1.3 \mathrm{mg} / \mathrm{kg})$, followed by ibrutinib $(2.9 \mathrm{mg} / \mathrm{kg})$ and spebrutinib $(20 \mathrm{mg} / \mathrm{kg})$. Because of the covalent nature of binding, BTK inhibitors have been shown to have a prolonged PD effect even as plasma drug levels fall to undetectable levels. To investigate this, a return-of-function experiment was performed investigating anti-IgM-induced CD69 expression on the splenocyte B cells and BTK target occupancy in the splenocytes. The potent biotinylated probe ACP-4016 (compound 10) was developed to support development of an ELISA-based BTK target occupancy assay (Fig. 4D). The biochemical $\mathrm{IC}_{50}$ value of the probe averaged 2.2 $\mathrm{nM}$ (Supplemental Table 1). Mice (five per group) were dosed orally with a single dose of acalabrutinib, ibrutinib, spebrutinib $(25 \mathrm{mg} / \mathrm{kg})$, or vehicle. Spleens were extracted $3,6,12,18$, or 24 hours after dosing and single-cell suspensions were prepared. Splenocytes were cultured and stimulated with anti-IgM for 18 hours, followed by measurement of CD69 surface expression (Fig. 4B), or they were used directly in the BTK target occupancy assay (Fig. 4C). Acalabrutinib and ibrutinib showed (near) complete BTK occupancy along with complete inhibition of anti-IgM-induced CD69 expression on splenocyte B cells for the 3-hour postdose time point. These results are in line with the dose-response data showing full inhibition of splenocyte $B$ cells at oral doses $\geq 10 \mathrm{mg} / \mathrm{kg}$ for acalabrutinib and ibrutinib, 3 hours after dosing. Additional experiments demonstrated that complete BTK target occupancy and full B cell deactivation was already achieved 1 hour after dosing (data not shown). In contrast, a $25-\mathrm{mg} / \mathrm{kg}$ dose of spebrutinib showed incomplete BTK target occupancy (approximately 15\% free BTK versus vehicle control) and inhibition of anti-IgM-induced CD69 expression on peripheral B cells (approximately 25\% remaining activity versus vehicle control). This again corresponded with the observed higher $\mathrm{ED}_{50}$ of $20 \mathrm{mg} / \mathrm{kg}$ for this BTK inhibitor. Over time, an increase in the amount of free BTK and an increase in splenocyte B cell function was demonstrated, as measured by function of anti-IgM-induced CD69 expression. However, BTK target occupancy and inhibition of B cell function was still observed 24 hours postdose. Acalabrutinib and ibrutinib displayed around $35 \%$ free BTK and $40 \%$ B cell activity versus vehicle control at 24 hours postdose, whereas approximately $55 \%$ free BTK and $75 \%$ splenocyte B cell activity was observed for spebrutinib at this time point. The average return rate for all three BTK inhibitors was estimated using linear fitting of the data for the return of B cell function (anti-IgM-induced CD69 expression on splenocyte B cells) and the return of free BTK. These return rates were $2.0 \% \pm 0.2 \%$ and $1.7 \% \pm 0.1 \%$ per hour, respectively.

PK/PD in Healthy Volunteers. The PK properties and safety of acalabrutinib were evaluated in a sequential doseescalation study in healthy adult volunteers (six per group) after oral administration of two doses of $2.5,5,25$, or $50 \mathrm{mg}$ given 12 hours apart on a single day and a single dose of either 75 or $100 \mathrm{mg}$. Acalabrutinib was rapidly absorbed, with median time to maximum plasma concentration ( $\left.T_{\max }\right)$ values between 0.5 and 1.0 hours for all dose cohorts, independent of dose level (Supplemental Fig. 2; Supplemental Table 5). The increase in mean $C_{\max }$ was greater than dose proportional from 5 to $25 \mathrm{mg}$. However, between 2.5-5.0, 25-50, and 50-100 mg, the increases in mean $C_{\max }$ were close to dose proportional. The mean values of $\mathrm{AUC}_{0-12}, \mathrm{AUC}_{0-24}$, and $\mathrm{AUC}_{0-\infty}$ increased in a dose-proportional manner based on the increases of the total dose administered (Fig. 5A). Linear regression analysis of the natural log (ln) transformed $\mathrm{AUC}_{0-24}$ and $\mathrm{AUC}_{0-\infty}$ relative to the $\ln$ transformed dose administered, indicated that the increases in AUC relative to the increases in dose administered were linear. Rapid elimination was observed, with mean $t_{1 / 2}$ values ranging from 0.88 to 2.1 hours in cohorts $1-5$. The mean calculated CL/F values ranged from 165 to $219 \mathrm{l} / \mathrm{h}$ and appeared to be independent of the dose administered. Vz/F values ranged from 233 to 612 liters and also appeared to be independent of the dose administered.

Of 59 enrolled subjects, 16 (27\%) reported one or more adverse events during the study. All adverse events were grade 1 or 2 . No serious adverse events occurred in the study. Of the adverse events reported, three (constipation, somnolence, and feeling cold) were assessed as related to acalabrutinib. No study drug-related adverse events led to discontinuation from the study. No effect of acalabrutinib was observed on any laboratory parameters (i.e., hematology, serum chemistry, urinalysis, cardiac troponin I, and C-reactive protein). No effect was 
A

Dose Response (po)

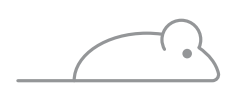
$3 h$ 3h $\begin{aligned} & \text { Extract } \\ & \text { Spleen }\end{aligned}$

CD69 Cell

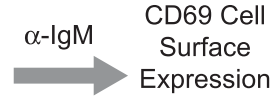

\section{In Vivo Potency}

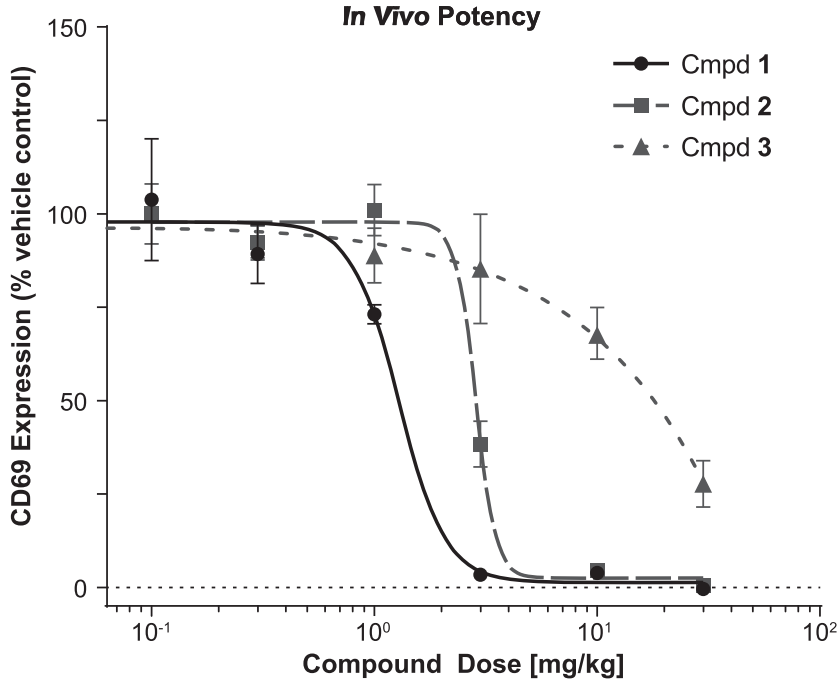

\begin{tabular}{l|c|c|c} 
& Cmpd 1 & Cmpd 2 & Cmpd 3 \\
\hline $\mathrm{ED}_{50}(\mathrm{mg} / \mathrm{kg})$ & 1.3 & 2.9 & 20 \\
\hline
\end{tabular}

C

Single Dose (25 mg/kg, po)

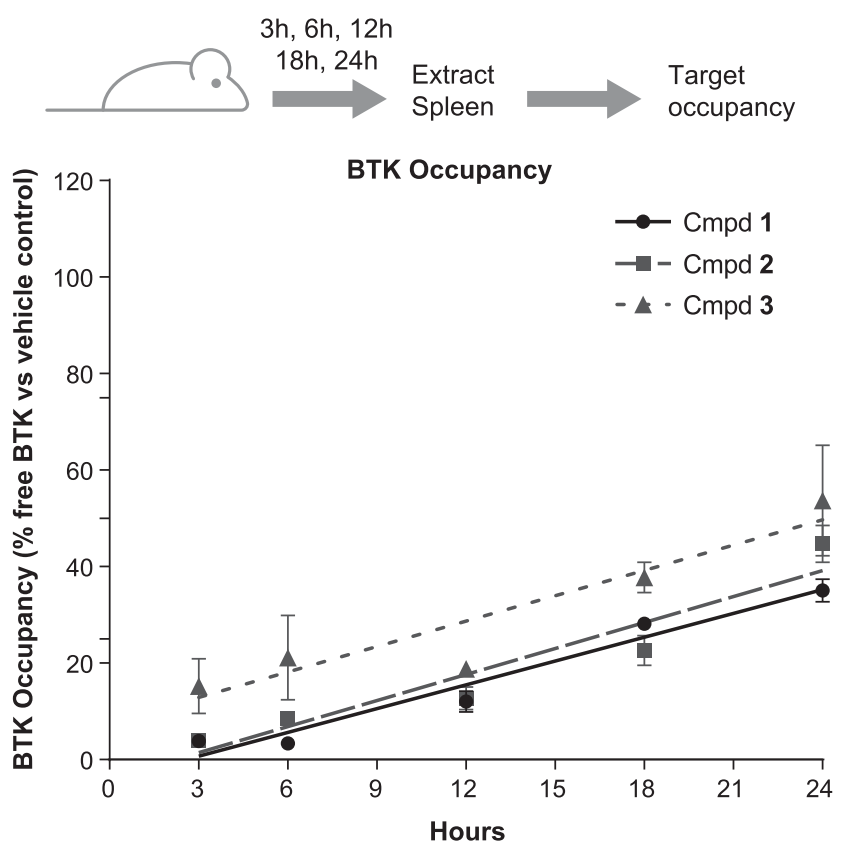

B

Single Dose (25 mg/kg, po)

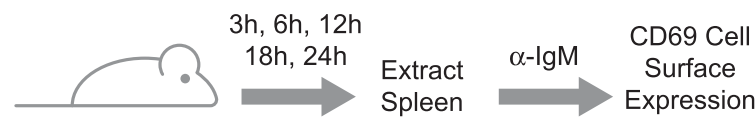

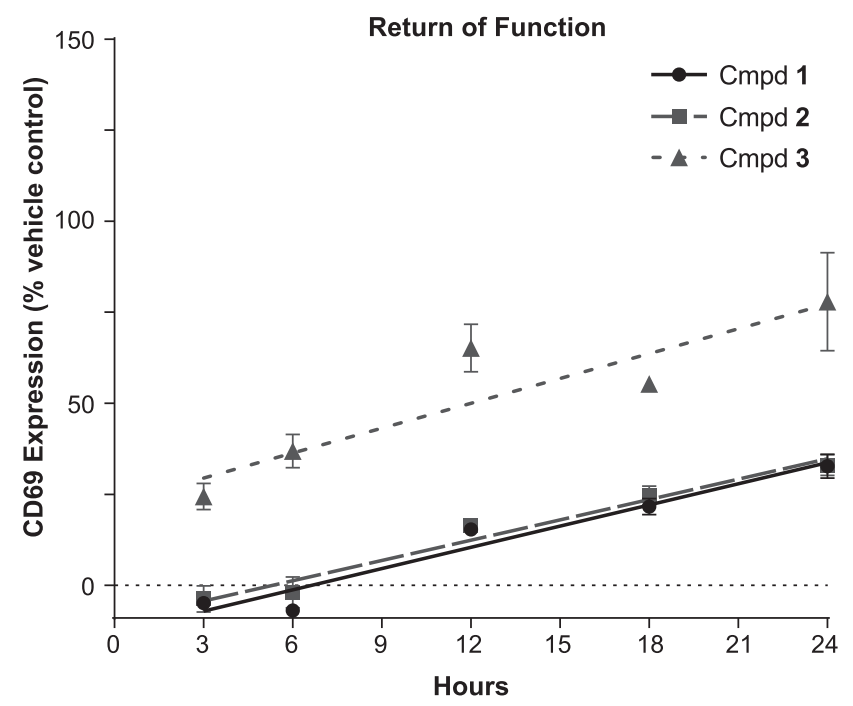

Fig. 4. (A) In vivo potency. Mice (five per group) were given an oral dose of acalabrutinib, ibrutinib, spebrutinib, or vehicle over a concentration range ( $x$-axis). After 3 hours, spleens were extracted and splenocytes were stimulated with anti-IgM for 18 hours, followed by CD69 expression analysis by flow cytometry gated on CD19+ B cells. The CD69 median fluorescent intensity values were normalized as a percentage of the vehicle control group and the mean average and S.E.M. were plotted for all mice in each dose cohort. (B) Return of function. Mice (five per group) received a single oral $25 \mathrm{mg} / \mathrm{kg}$ dose of acalabrutinib, ibrutinib, spebrutinib, or vehicle. Spleens were extracted 3, 6, 12, 18, or 24 hours after dosing and single-cell suspensions were made. Splenocytes were immediately cultured with anti-IgM for 18 hours, followed by CD69 surface expression measurement by flow cytometry as in (A). Data show CD69 expression for each mouse normalized as a percentage of the vehicle control group. Data presented are expansions from Herman et al. (2017). (C) BTK target occupancy was measured in the mouse splenocyte samples from the experiment described in (B). (D) Structure of the target occupancy probe ACP-4016 (compound 10). Cmpd, compound. 
A

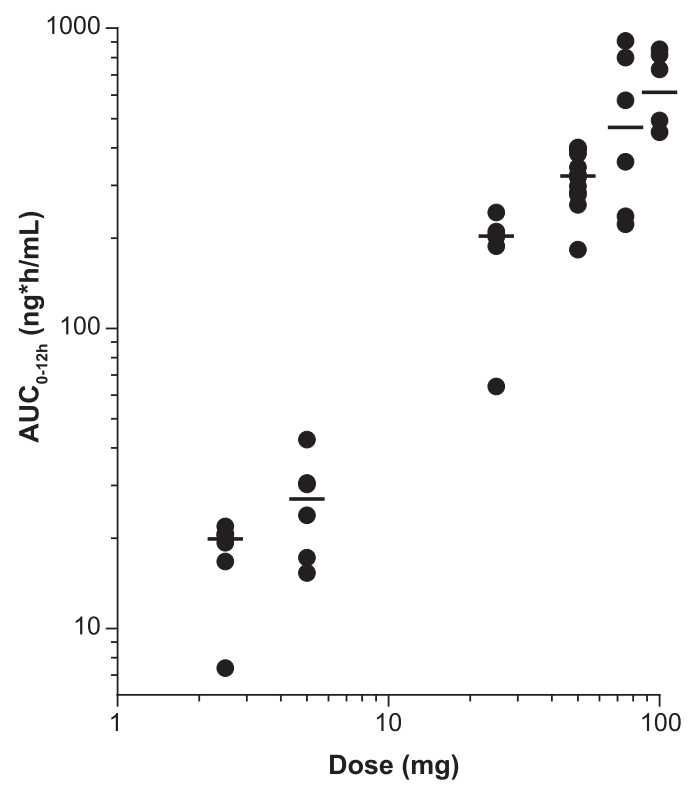

Fig. 5. PK versus $P D$ after acalabrutinib dose in healthy human volunteers. (A) Dose-exposure relationship of acalabrutinib in healthy subjects in study ACE-HV-001. Log/log presentation showing individual $\mathrm{AUC}_{0-12}$ values with medians (horizontal line) for a single dose of $2.5,5,25,50,75$, and $100 \mathrm{mg}$. (B and C) PD measurements, BTK target occupancy, and inhibition of anti-IgM-induced CD69 expression were derived from blood samples drawn from each subject 3 and 12 hours after acalabrutinib administration. Each point represents data from an individual blood sample, and each group median is represented by a horizontal line. (D) The mean acalabrutinib concentration in plasma $(n=6$; left axis, light gray) is plotted with median BTK occupancy $(n=4$; right axis, gray dotted) and median inhibition of BCR-induced CD69 protein expression on B cells $(n=5$; right axis, black) from individuals who received a single 100-mg dose. Error bars show the S.D. for acalabrutinib plasma concentration. For the BTK occupancy and CD69 inhibition data, error bars show the interquartile range. BTK occupancy data are corrected for changes in $\mathrm{B}$ cell numbers.
B

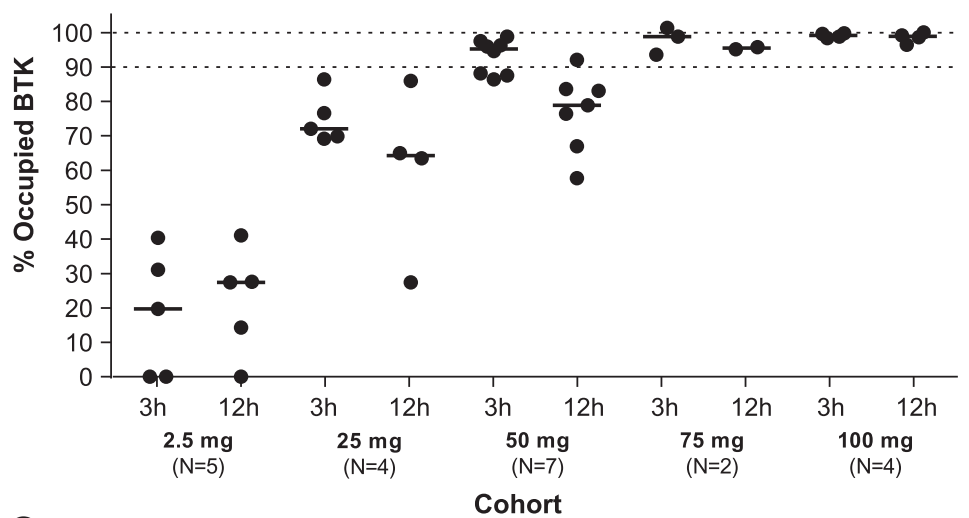

C
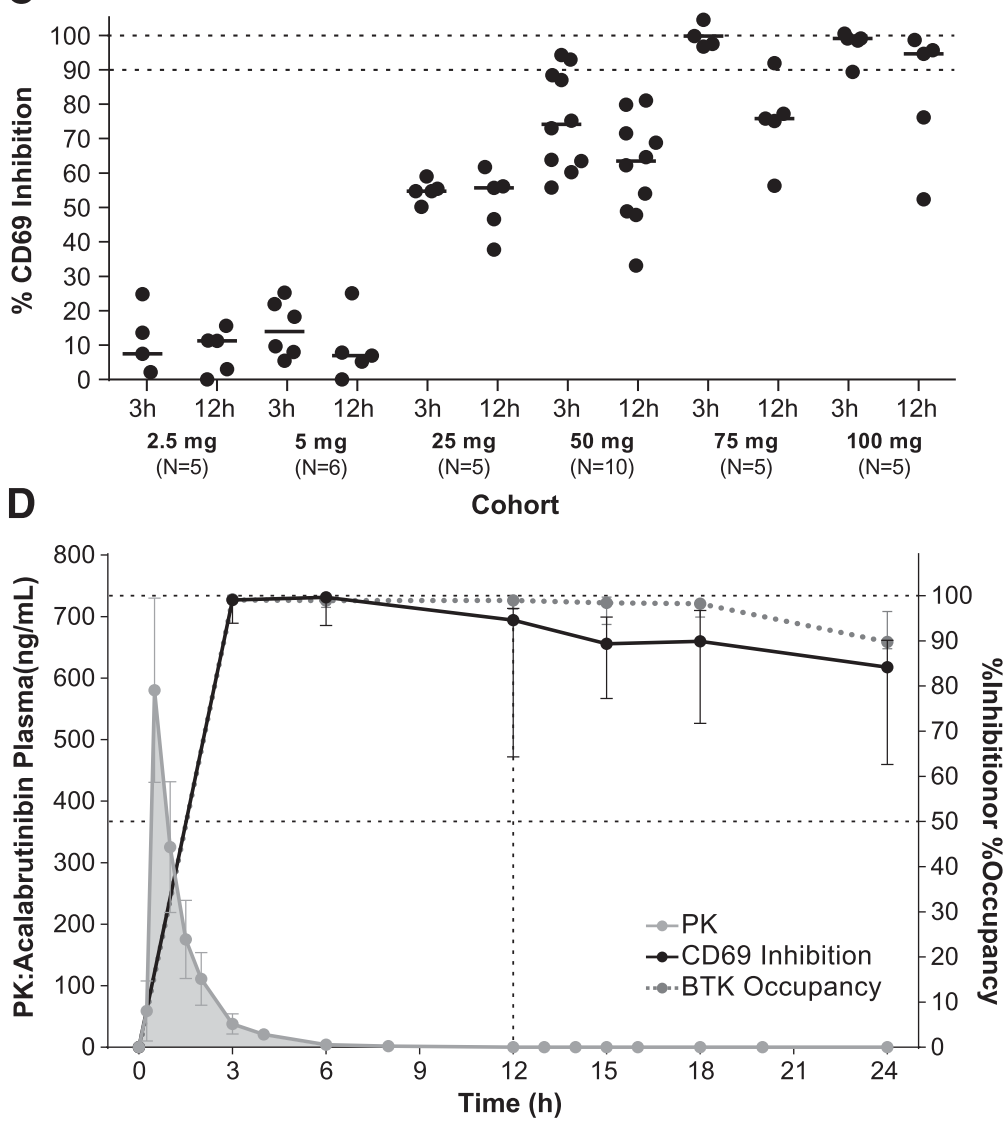

observed of acalabrutinib on physical examinations, vital signs, or electrocardiography parameters.

The PD of acalabrutinib was evaluated using the BTK occupancy assay and measuring the inhibition of CD69 expression on B cells after ex vivo BCR stimulation. Both PD readouts were dose dependent, with a plateau observed at the 75- and 100-mg dose levels, 3 hours after acalabrutinib administration. At this time point, the degree of BTK median occupancy was around $99 \%$ for the 75 - and 100-mg doses (Fig. 5B). This correlated with near complete inhibition for CD69 (Fig. 5C) for the same doses and time point. However, only the $100-\mathrm{mg}$ cohort maintained high BTK median occupancy and high BCR functional inhibition over time (Fig. 5D). At 12 hours, the median occupancy was 99\% and the median CD69 inhibition was 95\%, whereas these parameters were $90 \%$ and $84 \%$ at 24 hours, respectively. CD86 expression levels were also determined in parallel and essentially matched the inhibition of CD69 expression (data not shown).

\section{Discussion}

Acalabrutinib was identified as a BTK inhibitor with a differentiated kinase selectivity profile compared with other BTK inhibitors in development. Key structural components of acalabrutinib include a 2-pyridylbenzamide moiety and the electrophilic 2-butynamide moiety that is involved in covalent binding to Cys481. The proximal positioning of the 2-butynamide moiety to the electron-deficient (and thus electron-withdrawing) imidazopyrazine core may help to reactivate this otherwise 
fairly inert functionality. The potency difference of the enantiomeric pair (compare acalabrutinib and compound 4) showed that the activity primarily resides in the $S$-enantiomer, suggesting better positioning of the butynamide moiety. As demonstrated in the GSH assay, acalabrutinib displayed lower reactivity than acrylamides ibrutinib, spebrutinib, and compound 7. This may help to minimize inhibition of offtarget cysteine kinases that exhibit higher cysteine $\mathrm{p} K_{\mathrm{a}}$ values than that for Cys 481 in BTK. Indeed, acalabrutinib is the most selective with regard to inhibition of TEC-, EGFR-, and SRC-family kinases. The correlation of biochemical offtarget inhibition and functional consequences in selected cell lines was confirmed for different kinases.

Inhibitors of the EGFR signaling pathway cause skin rash and diarrhea, and these toxicities are believed to be "class effects" (Lynch et al., 2007; Dy and Adjei, 2013). With respect to the inhibitory potential for EGFR, the rank order of compounds was identical in biochemical and cellular settings, with acalabrutinib showing a lack of functional inhibitory effects $\left(\mathrm{EC}_{50}>10 \mu \mathrm{M}\right)$. The events of diarrhea reported during acalabrutinib treatment of patients with CLL (grades 1 to 2, 38\%; all grades, 39\%) have been generally mild (Byrd et al., 2016). Given the observed exposure levels of acalabrutinib after a single oral dose of $100 \mathrm{mg}$ $(580 \pm 150 \mathrm{ng} / \mathrm{ml})$ and the absence of effects on phosphoEGFR inhibition in two relevant cell lines at these concentrations, we do not expect to see EGFR-mediated adverse events for acalabrutinib.

ITK signaling in Jurkat cells and in primary human peripheral $\mathrm{T}$ cells correlated with the biochemical IMAP data. The drug concentrations needed to inhibit IL-2 production in Jurkat cells and modulation of human peripheral $\mathrm{T}$ cells may well be achieved in patients treated with ibrutinib or spebrutinib (Dubovsky et al., 2013; Evans et al., 2013) and therefore may bear physiologic relevance. Indeed, ibrutinib is a reported irreversible covalent ITK inhibitor with confirmed occupancy on this kinase in patients with CLL (Dubovsky et al., 2013). Treatment with ibrutinib reduced the number of Th $17 \mathrm{~T}$ cells as a percentage of the total $\mathrm{T}$ cell population in patients with CLL, as well as Th17 development from mouse naïve CD4+ T cells. The mouse observations are in line with data reported for $\mathrm{ITK}^{-1-}$ mice, in which a shift in the balance from Th17 to regulatory T cells was observed (Gomez-Rodriguez et al., 2014). The same authors reported that this effect is even more pronounced in ITK/TXK ${ }^{-1-}$ mice (Gomez-Rodriguez et al., 2011), indicating redundancy between ITK and TXK. Since ibrutinib inhibited both ITK and TXK in the low nanomolar range in the biochemical assays, the effects of ibrutinib on $\mathrm{T}$ cell differentiation most likely mimic the double-knockout phenotype. ITK is also expressed in natural killer (NK) cells (Khurana et al., 2007), and inhibition thereof has been reported to decrease the antibody-dependent cellular cytotoxicity function of NK cells (Kohrt et al., 2014). It was reported that ibrutinib inhibited both rituximab- and trastuzumab-induced NK cell cytokine secretion and lysis in vitro in a dose-dependent manner $(0.1$ and $1 \mu \mathrm{M})$, whereas acalabrutinib did not show any effects at $1 \mu \mathrm{M}$ (Rajasekaran et al., 2014). This indicates that acalabrutinib is associated with a reduced risk of affecting antibody-dependent cellular cytotoxicity-mediated therapies.

An increased incidence in severe hemorrhage was reported in patients treated with ibrutinib and has been attributed to the effect of ibrutinib on several distinct signaling pathways (Byrd et al., 2015; Wang et al., 2015; Shatzel et al., 2017). Therefore, patients receiving ibrutinib are monitored to reduce the potential risk for bleeding. Although the role of BTK on collagen-induced platelet aggregation has been well described, there is no general increase of bleeding risk in patients with X-linked agammaglobulinemia lacking functional BTK (Quek et al., 1998; Winkelstein et al., 2006), suggesting that BTK inhibition alone is likely not responsible for increased bleeding risk. In platelets, the downstream signaling of several receptors on platelets, including the platelet collagen receptor glycoprotein VI and C-type lectin-like receptor 2, is mediated by BTK and TEC (Shatzel et al., 2017). Earlier, we reported on differences in platelet aggregation using platelets from patients treated with acalabrutinib or ibrutinib (Byrd et al., 2016). In an in vivo thrombus formation model, diminished platelet reactivity was observed in samples from patients treated with ibrutinib, whereas platelets from acalabrutinib-treated patients showed similar reactivity to those derived from nontreated healthy controls. Because TEC kinase phosphorylation is highly dependent on platelet aggregation (Hamazaki et al., 1998; Atkinson et al., 2003), the level of TEC inhibition may govern the bleeding risk. The relative biochemical $\mathrm{IC}_{50}$ values for TEC of acalabrutinib (126 $\mathrm{nM})$ and ibrutinib (10 $\mathrm{nM})$ may well contribute to the observed differences in the above model. In addition, inhibition of SRC-family kinases by ibrutinib may play a role in the observed bleeding incidence in ibrutinibtreated patients through modulation of fibrinogen- and von Willebrand factor-induced platelet activation (Séverin et al., 2012; Senis et al., 2014). Regulation of SRC-mediated platelet activation may be anticipated at exposure levels observed in patients that are treated with ibrutinib. For instance, Patel et al. (2017) reported that ibrutinib demonstrated potent inhibition of phosphorylation of SRC family members LCK and SRC in T cells, with an $\mathrm{EC}_{50}$ of $<0.2 \mu \mathrm{M}$, whereas the $\mathrm{EC}_{50}$ for acalabrutinib was not reached at $10 \mu \mathrm{M}$. Again, these data correspond well with the nanomolar inhibition by ibrutinib for both SRC and LCK. Taken together, these observations indicate that effects of ibrutinib on bleeding could be multifactorial. The improved selectivity profile of acalabrutinib for BTK versus TEC and SRC-family kinases may prove advantageous in this regard.

Overall, the biochemical potency of all compounds tested for BTK activity traced well with the inhibitory potential of marker CD69 in our PBMC and hWB assays, except for spebrutinib. For instance, the potency of BTK-mediated inhibition of peripheral B cell function in hWB was approximately 15-fold lower for spebrutinib than for acalabrutinib and ibrutinib. This suggests that plasma proteins or other components of hWB (e.g., red blood cells, platelets, or neutrophils) may contribute to a lower free fraction of spebrutinib that is available for BTK inhibition. The in vivo potency data generated in the mouse PD model mirrored the cellular data generated, except that acalabrutinib showed better potency than ibrutinib in vivo. With spebrutinib, efficacy could be obtained at higher dosages, but potency was inferior to acalabrutinib and ibrutinib. Evaluation of return of free BTK and return of B cell function in mice demonstrated that the return rate is independent of the type of BTK inhibitor tested. Hence, the de novo synthesis rate of BTK is the primary driver for the loss of PD effect in a single dose setting. 
In human healthy subjects, acalabrutinib is an orally bioavailable BTK inhibitor with fast absorption, doseproportional PK, and a short half-life in the systemic circulation. Despite the short half-life, acalabrutinib had a pronounced on-target impact in peripheral blood B cells that was dose dependent. Complete BTK occupancy was observed 3 and 12 hours after a single 100 -mg dose, indicating that a saturating concentration was achieved that resulted in near complete inhibition of a BCR-induced functional response (i.e., CD69 expression). Both measures remained high for 24 hours. Therefore, covalent modification of BTK by acalabrutinib prolonged target occupancy and PD that extend beyond the relatively short plasma half-life in healthy volunteers. In patient populations with more rapidly proliferating B cells, we anticipate an increased de novo synthesis rate of BTK, suggesting that more frequent dosing may be required to achieve optimal BTK inhibition. Indeed, a 100-mg twicedaily dose in patients with CLL showed a higher median BTK occupancy, with less variability at trough, than the 100- and 250-mg/d cohorts (Byrd et al., 2016). This illustrates that maximal target coverage can be achieved with twice-daily dosing, which we believe is advantageous for optimal treatment across patient populations with B cell malignancies.

In conclusion, monitoring structure-reactivity relationships may help to mitigate the risk for off-target adverse events related to reactivity of the electrophile (Barf and Kaptein, 2012). Low electrophilicity is an important feature to consider to progress the most suitable covalent inhibitor candidates through the pipeline. The use of a straightforward GSH assay to assess the likelihood and the kinetics of covalent binding revealed a difference in reactivity between compounds containing butynamide and acrylamide moieties. We believe that the lower electrophilicity of acalabrutinib along with the higher nucleophilicity of Cys481 in BTK contributes to the observed selectivity profile, which may reduce off-target mediated adverse events. In combination with the improved in vivo potency, acalabrutinib appears to have a differentiated preclinical profile from ibrutinib and spebrutinib. Selective covalent BTK probe 10 helped to confirm the correlation of the degree of BTK occupancy and engagement by acalabrutinib in preclinical and clinical settings. Acalabrutinib is a rapidly absorbed covalent BTK inhibitor with a short half-life, yet it reaches full target occupancy at a single oral dose of $100 \mathrm{mg}$ in healthy human subjects. Clinical evaluation of acalabrutinib in multiple B cell malignancies, solid tumors, and selected autoimmune indications is currently in progress.

\section{Acknowledgments}

The authors thank Anouk de Jong for performing the PBMC T cell assays, Tim Ingallinera for preparing the in vivo formulations for the mouse PD experiments, Gerjan de Bruin for analysis of the $K_{\mathrm{I}}$ and $k_{\text {inact }}$ data, and Greg Slatter for the discussion on the human PK/PD data. BioAxis Research BV is acknowledged for the $\mathrm{p} K_{\mathrm{a}}$ modeling of kinase cysteines. Final versions of the figures were created by Cognition Studios. This article reveals the reflections of the authors on some of the research and data regarding acalabrutinib. This research has spanned many years and is ongoing. This article does not attempt to address exhaustively every aspect and detail of that research. All authors are employees of or consultants to and are shareholders of Acerta Pharma BV.

\section{Authorship Contributions}

Participated in research design: Barf, Covey, Izumi, Gulrajani, Mittag, Pearson, Ulrich, Kaptein.

Conducted experiments: Barf, van de Kar, Gulrajani, van Lith, van Hoek, de Zwart, Mittag, Demont, Verkaik, Krantz.

Performed data analysis: Barf, Covey, Izumi, van de Kar, Gulrajani, van Lith, van Hoek, de Zwart, Mittag, Demont, Verkaik, Krantz, Pearson, Kaptein.

Wrote or contributed to the writing of the manuscript: Barf, Covey, Izumi, Pearson, Kaptein.

\section{References}

Atkinson BT, Ellmeier W, and Watson SP (2003) Tec regulates platelet activation by GPVI in the absence of Btk. Blood 102:3592-3599.

Barf T and Kaptein A (2012) Irreversible protein kinase inhibitors: balancing the benefits and risks. $J$ Med Chem 55:6243-6262.

Bender AT, Pereira A, Fu K, Samy E, Wu Y, Liu-Bujalski L, Caldwell R, Chen Y-Y, Tian H, Morandi F, et al. (2016) Btk inhibition treats TLR7/IFN driven murine lupus. Clin Immunol 164:65-77.

Brown JR, Harb WA, Hill BT, Gabrilove J, Sharman JP, Schreeder MT, Barr PM, Foran JM, Miller TP, Burger JA, et al. (2016) Phase I study of single-agent CC-292, a highly selective Bruton's tyrosine kinase inhibitor, in relapsed/refractory chronic lymphocytic leukemia. Haematologica 101:e295-e298.

Byrd JC, Furman RR, Coutre SE, Burger JA, Blum KA, Coleman M, Wierda WG, Jones JA, Zhao W, Heerema NA, et al. (2015) Three-year follow-up of treatmentnaïve and previously treated patients with CLL and SLL receiving single-agent ibrutinib. Blood 125:2497-2506.

Byrd JC, Harrington B, O'Brien S, Jones JA, Schuh A, Devereux S, Chaves J, Wierda WG, Awan FT, Brown JR, et al. (2016) Acalabrutinib (ACP-196) in relapsed chronic lymphocytic leukemia. $N$ Engl J Med 374:323-332.

Byrd JC, O'Brien S, and James DF (2013) Ibrutinib in relapsed chronic lymphocytic leukemia. N Engl J Med 369:1278-1279.

de Weers M, Verschuren MC, Kraakman ME, Mensink RG, Schuurman RK, van Dongen JJ, and Hendriks RW (1993) The Bruton's tyrosine kinase gene is expressed throughout B cell differentiation, from early precursor B cell stages preceding immunoglobulin gene rearrangement up to mature B cell stages. Eur J Immunol 23:3109-3114.

Dubovsky JA, Beckwith KA, Natarajan G, Woyach JA, Jaglowski S, Zhong Y, Hessler JD, Liu T-M, Chang BY, Larkin KM, et al. (2013) Ibrutinib is an irreversible molecular inhibitor of ITK driving a Th1-selective pressure in T lymphocytes. Blood 122:2539-2549.

Dy GK and Adjei AA (2013) Understanding, recognizing, and managing toxicities of targeted anticancer therapies. CA Cancer J Clin 63:249-279.

Ellmeier W, Abramova A, and Schebesta A (2011) Tec family kinases: regulation of FceRI-mediated mast-cell activation. FEBS $J$ 278:1990-2000.

Evans EK, Tester R, Aslanian S, Karp R, Sheets M, Labenski MT, Witowski SR, Lounsbury H, Chaturvedi P, Mazdiyasni H, Zhu Z, et al. (2013) Inhibition of Btk with CC-292 provides early pharmacodynamic assessment of activity in mice and humans. J Pharmcol Exp Ther 346:219-228.

Garske AL, Peters U, Cortesi AT, Perez JL, and Shokat KM (2011) Chemical genetic strategy for targeting protein kinases based on covalent complementarity. Proc Natl Acad Sci USA 108:15046-15052.

Gomez-Rodriguez J, Kraus ZJ, and Schwartzberg PL (2011) Tec family kinases Itk and Rlk/Txk in T lymphocytes: cross-regulation of cytokine production and T-cell fates. FEBS $J$ 278:1980-1989.

Gomez-Rodriguez J, Wohlfert EA, Handon R, Meylan F, Wu JZ, Anderson SM, Kirby MR, Belkaid Y, and Schwartzberg PL (2014) Itk-mediated integration of T cell receptor and cytokine signaling regulates the balance between Th17 and regulatory T cells. J Exp Med 211:529-543.

Grenningloh R (2016) Discovery of the highly specific BTK inhibitor M2951 and pharmacodynamic modeling of BTK occupancy versus efficacy in RA and SLE models. 14th Annual Discovery on Target; 2016 Sep 19-22; Boston, MA

Hamazaki Y, Kojima H, Mano H, Nagata Y, Todokoro K, Abe T, and Nagasawa T (1998) Tec is involved in G protein-coupled receptor- and integrin-mediated signalings in human blood platelets. Oncogene 16:2773-2779.

Hendriks RW, Yuvaraj S, and Kil LP (2014) Targeting Bruton's tyrosine kinase in B cell malignancies. Nat Rev Cancer 14:219-232.

Herman SEM, Montraveta A, Niemann CU, Mora-Jensen H, Gulrajani M, Krantz F, Mantel R, Smith LL, McClanahan F, Harrington BK, et al. (2017) The Bruton tyrosine kinase (BTK) inhibitor acalabrutinib demonstrates potent on-target effects and efficacy in two mouse models of chronic lymphocytic leukemia. Clin Cancer Res 23:2831-2841.

Honigberg LA, Smith AM, Sirisawad M, Verner E, Loury D, Chang B, Li S, Pan Z, Thamm DH, Miller RA, et al. (2010) The Bruton tyrosine kinase inhibitor PCI-32765 blocks B-cell activation and is efficacious in models of autoimmune disease and B-cell malignancy. Proc Natl Acad Sci USA 107:13075-13080.

Jongstra-Bilen J, Puig Cano A, Hasija M, Xiao H, Smith CI, and Cybulsky MI (2008) Dual functions of Bruton's tyrosine kinase and Tec kinase during Fcgamma receptor-induced signaling and phagocytosis. J Immunol 181:288-298.

Katz FE, Lovering RC, Bradley LA, Rigley KP, Brown D, Cotter F, Chessells JM, Levinsky RJ, and Kinnon C (1994) Expression of the X-linked agammaglobulinemia gene, btk in B-cell acute lymphoblastic leukemia. Leukemia 8:574-577.

Khurana D, Arneson LN, Schoon RA, Dick CJ, and Leibson PJ (2007) Differential regulation of human NK cell-mediated cytotoxicity by the tyrosine kinase Itk. J Immunol 178:3575-3582. 
Kohrt HE, Sagiv-Barfi I, Rafiq S, Herman SEM, Butchar JP, Cheney C, Zhang X, Buggy JJ, Muthusamy N, Levy R, et al. (2014) Ibrutinib antagonizes rituximabdependent NK cell-mediated cytotoxicity. Blood 123:1957-1960.

Kortemme T and Creighton TE (1995) Ionisation of cysteine residues at the termini of model alpha-helical peptides. Relevance to unusual thiol $\mathrm{p} K_{\mathrm{a}}$ values in proteins of the thioredoxin family. J Mol Biol 253:799-812.

Lynch TJ, Jr, Kim ES, Eaby B, Garey J, West DP, and Lacouture ME (2007) Epidermal growth factor receptor inhibitor-associated cutaneous toxicities: an evolving paradigm in clinical management. Oncologist 12:610-621.

Norman P (2016) Investigational Bruton's tyrosine kinase inhibitors for the treatment of rheumatoid arthritis. Exp Opin Invest Drugs 25:891-899.

O'Brien S, Furman RR, Coutre SE, Sharman JP, Burger JA, Blum KA, Grant B Richards DA, Coleman M, Wierda WG, et al. (2014) Ibrutinib as initial therapy for elderly patients with chronic lymphocytic leukaemia or small lym phocytic lymphoma: an open-label, multicentre, phase 1b/2 trial. Lancet Oncol 15:48-58.

Pan Z, Scheerens H, Li S-J, Schultz BE, Sprengeler PA, Burrill LC, Mendonca RV, Sweeney MD, Scott KCK, Grothaus PG, et al. (2007) Discovery of selective irreversible inhibitors for Bruton's tyrosine kinase. ChemMedChem 2:58-61.

Park JK, Byun J-Y, Park JA, Kim Y-Y, Lee YJ, Oh JI, Jang SY, Kim YH, Song YW, Son J, et al. (2016) HM71224, a novel Bruton's tyrosine kinase inhibitor, suppresses B cell and monocyte activation and ameliorates arthritis in a mouse model: a potential drug for rheumatoid arthritis. Arthritis Res Ther 18:91.

Patel V, Balakrishnan K, Bibikova E, Ayres M, Keating MJ, Wierda WG, and Gandhi V (2017) Comparison of acalabrutinib, a selective Bruton tyrosine kinase inhibitor, with ibrutinib in chronic lymphocytic leukemia cells. Clin Cancer Res 23: 3734-3743.

Ponader S and Burger JA (2014) Bruton's tyrosine kinase: from X-linked agammaglobulinemia toward targeted therapy for B-cell malignancies. J Clin Oncol 32 1830-1839.

Quek LS, Bolen J, and Watson SP (1998) A role for Bruton's tyrosine kinase (Btk) in platelet activation by collagen. Curr Biol 8:1137-1140.

Rajasekaran N, Sadaram M, Hebb J, Sagiv-Barfi I, Ambulkar S, Rajapaksa A, Chang S, Chester C, Waller E, Wang L, et al. (2014) Three BTK-specific inhibitors, in contrast to ibrutinib, do not antagonize rituximab-dependent NK-cell mediated cytotoxicity. Blood 124:3118.

Senis YA, Mazharian A, and Mori J (2014) Src family kinases: at the forefront of platelet activation. Blood 124:2013-2024.
Séverin S, Nash CA, Mori J, Zhao Y, Abram C, Lowell CA, Senis YA, and Watson SP (2012) Distinct and overlapping functional roles of Src family kinases in mouse platelets. J Thromb Haemost 10:1631-1645.

Shatzel JJ, Olson SR, Tao DL, McCarty OJT, Danilov AV, and DeLoughery TG (2017) Ibrutinib-associated bleeding: pathogenesis, management and risk reduction strategies. J Thromb Haemost 15:835-847.

Smith PF, Krishnarajah J, Nunn PA, Hill RJ, Karr D, Tam D, Masjedizadeh M, and Gourlay SG (2015) A phase 1 clinical trial of PRN1008, an oral, reversible, covalent BTK inhibitor demonstrates clinical safety and therapeutic levels of BTK occupancy without sustained systemic exposure (Abstract). Ann Rheum Dis 74 (Suppl 2):742.

Tam C, Grigg AP, Opat S, Ku M, Gilberson M, Anderson MA, Seymour JF, Ritchie DS, Dicorleto C, Dimovski B, et al. (2015) The BTK inhibitor, Bgb-3111, is safe, tolerable, and highly active in patients with relapsed/ refractory B-cell malignancies: initial report of a phase 1 first-in-human trial. Blood 126:832.

Walter HS, Rule SA, Dyer MJS, Karlin L, Jones C, Cazin B, Quittet P, Shah N, Hutchinson CV, Honda H, et al. (2016) A phase 1 clinical trial of the selective BTK inhibitor ONO/GS-4059 in relapsed and refractory mature B-cell malignancies. Blood 127:411-419.

Wang ML, Blum KA, Martin P, Goy A, Auer R, Kahl BS, Jurczak W, Advani RH Romaguera JE, Williams ME, et al. (2015) Long-term follow-up of MCL patients treated with single-agent ibrutinib: updated safety and efficacy results. Blood 126:739-745.

Wang ML, Rule S, Martin P, Goy A, Auer R, Kahl BS, Jurczak W, Advani RH, Romaguera JE, Williams ME, et al. (2013) Targeting BTK with ibrutinib in relapsed or refractory mantle-cell lymphoma. $N$ Engl J Med 369:507-516.

Whang JA and Chang BY (2014) Bruton's tyrosine kinase inhibitors for the treatment of rheumatoid arthritis. Drug Discov Today 19:1200-1204.

Winkelstein JA, Marino MC, Lederman HM, Jones SM, Sullivan K, Burks AW, Conley ME, Cunningham-Rundles C, and Ochs HD (2006) X-linked agammaglobulinemia: report on a United States registry of 201 patients. Medicine (Baltimore) 85:193-202.

Zapf CW, Gerstenberger BS, Xing L, Limburg DC, Anderson DR, Caspers N, Han S, Aulabaugh A, Kurumbail R, Shakya S, et al. (2012) Covalent inhibitors of interleukin-2 inducible T cell kinase (itk) with nanomolar potency in a whole-blood assay. J Med Chem 55:10047-10063.

Address correspondence to: Tjeerd Barf, Acerta Pharma BV, Kloosterstraat 9, 5349 AB Oss, The Netherlands. E-mail: t.barf@acerta-pharma.com 